\title{
Identification of the Quadrature Resonances Using Modal Nonsynchronous Perturbation Testing and Dynamic Stiffness Approach for an Anisotropic Rotor System with Fluid Interaction.
}

\author{
EUNGU JANG \\ Research Engineer, Bently Rotor Dynamics Research Corporation, P.O.BOX 2529, Minden, Nevada 89423, U.S.A
}

AGNES MUSZYNSKA

Ph.D., Research Manager, Bently Rotor Dynamics Research Corporation, P.O.BOX 2529, Minden, Nevada 89423, U.S.A

YOUNG-PIL PARK

Ph.D., Professor, Dept. of Mechanical Engineering, Yonsei University, 134 Shinchon-Dong, Suhdamoon-Ku, Seoul, Korea.

CHANG-HO KIM

Ph.D., Senior Researcher, Korea Institute of Science and Technology, P.O.BOX 131, 130-650 Cheong Ryang, Seoul, Korea.

\begin{abstract}
The paper presents the dynamic analysis of an anisotropic rotor system with fluid interaction by using modal nonsynchronous perturbation testing and dynamic stiffness approaches. The anisotropic rotor system produces more complex rotor behavior than an isotropic system. In particular, the existence of the quadrature resonance phenomenon for backward precession is demonstrated. A symmetric rotor supported anisotropically by one fluid lubricated bearing and one rolling element bearing simulates rotating machinery behavior. A dynamic stiffness anisotropy algorithm which includes fluid terms is used to process experimental data in order to identify lightly loaded journal fluid film force parameters. The existence of the quadrature resonance for backward precession obtained from the experiment is compared with the analytical model. The results from modeling show strong agreement with experimental results.
\end{abstract}

Key Words: Anisotropy; fluid interaction; quadrature resonance phenomenon; dynamic stiffness anisotropy algorithm; modal nonsynchronous perturbation

\section{INTRODUCTION}

I $n$ spite of the interest and extensive research, it is not easy to obtain adequate information on rotating systems, due to their complexity and diversity. For several decades, the models of rotating systems have been continuously improving based on rotating machine field data and experimental research results. Since the development of the simple, isotropic, Jeffcott rotor model in 1919, various theoretical and experimental approaches, such as modal testing methods, multi-mode modeling, and consideration of fluid effects (Muszynska [1986, 1994], Subbiah et al [1989] and Tam et al [1988]), have been implemented to produce meaningful insight into the system dynamics. Fluid involved in rotational motion, mainly due to shaft rotation, has an interactive effect on the system behavior. Due to fluid interaction, there exist rotor self-excited vibrations which are known as fluid whirl and whip (Muszynska [1986]). From the earlier work, including an explanation of the fluid-related rotor response, stability threshold (Poritsky [1953]), and rotating character of fluid force (Black [1969]), to the introduction of fluid circumferential average velocity ratio and the experimental identification of the fluid force model in lightly loaded bearings and seals (Muszynska [1986] and Bently [1988]), many researchers have contributed to improvements in dynamic models of rotor vibrations. There is still a room for further improvements as most results were obtained for isotropic rotors. The research on isotropic models have provided valuable 
results; however, anisotropy must be considered in order to analyze more complex behavior of rotating machinery.

There are many sources which contribute to the rotating system anisotropy. The anisotropy natures of rotor system which depends on operating conditions produces more complicated rotor behavior. Anisotropy can be produced by internal and external sources such as misalignment, fluid interaction, nonsymmetry of support components, etc. Several diagnostic methods have been developed to verify the presence of anisotropy based on rotor response. Graphic tools such as elliptical synchronous orbits, Bode and polar plots exhibiting "split resonances," and transducer axis simulated rotation methodology have been introduced by Hatch and Bently [1995]. Dynamic parameters, or characteristics of a machine or structure include natural frequencies, mode shapes, damping, and such modal properties as stiffness and mass as a system parameters. To analyze the dynamic behavior of a mechanical system, parameter identification is an essential step. Extended modal testing techniques (Nordmann [1983], Muszynska [1986], Rogers and Ewins [1989]), which were developed to overcome the limitations of classical passive structuie modal testing, are widely used to quantify parameters of rotating machinery. Nordmann [1983] has used impact technique to evaluate the stiffness, damping coefficients of bearings, and considered some difference between nonrotating and rotating system. Roger and Ewins [1989] extended modal testing techniques to apply rotating machines by using a modified shaker. Muszynska [1986] has used synchronous perturbation testing, and nonsynchronous perturbation testing using swept frequency forces for identification of rotating machines. One of them, the modal nonsynchronous perturbation testing methodology by Muszynska [1986, 1990, 1995] has proven to be a powerful tool, as it enables independent identification of forward and backward modes of the rotating machine rotors.

In this paper, a symmetric rotor supported anisotropically by one relatively rigid and one fluid-lubricated bearing is considered in a range of frequencies which includes the fluid-induced resonance (Muszynska [1995]). Modal nonsynchronous perturbation testing is applied to the system in both forward and backward directions. A dynamic stiffness (Muszynska and Bently $[1984,1990])$ data processing identification algorithm is developed for the use with a two real degree of freedom anisotropic rotor model. The model includes fluid inertia effects. The existence of a previously undocumented resonance phenomenon for the backward precession, which exists only under anisotropy, is demonstrated.

\section{SYSTEM MODEL AND ANISOTROPY ALGORITHM}

The rotor is assumed to be symmetric, and supported anisotropically by one rigid and one fluid lubricated bearing. The system model, based on the discretized modal consideration of rotor displacement, can be represented by two lateral modes. The model contains the fluid-induced force (including fluid inertia effect) that was developed for lightly loaded bearings and for seals by Muszynska [1988, 1995]. The mathematical model in terms of rotor two lateral orthogonal displacement model at the bearing location is as follows:

$$
\begin{gathered}
M \ddot{x}+D_{s} \dot{x}+M_{f x}\left(\ddot{x}+2 \lambda_{x} \Omega \dot{y}-\lambda_{x}^{2} \Omega^{2} x\right)+D_{x}\left(\dot{x}+\lambda_{x} \Omega y\right) \\
+\left(K_{s}+K_{s p x}+K_{B x}\right) x=f_{x} \\
M \ddot{y}+D_{s} \dot{y}+M_{f y}\left(\ddot{y}-2 \lambda_{y} \Omega \dot{x}-\lambda_{y}^{2} \Omega^{2} y\right)+D_{y}\left(\dot{y}-\lambda_{y} \Omega x\right) \\
+\left(K_{s}+K_{s p y}+K_{B y}\right) y=f_{y} \\
j=\sqrt{-1} \cdot \cdot=d / d t
\end{gathered}
$$

where $M, D_{s}, D, M_{f}, \lambda, f$ are modal mass, shaft damping, fluid film radial damping, fluid inertia effect, fluid circumferential average velocity ratio, and circular unbalance perturbation forces, respectively; $K_{s}, K_{s p}, K_{B}$ are the shaft stiffness, external supporting spring stiffness, and fluid film radial direct stiffness, respectively; $x, y, \omega$ and $\Omega$ are rotor horizontal and vertical displacements, nonsynchronous perturbation frequency, and rotative speed respectively. The subscripts $x$ and $y$ denote values of corresponding parameters in $x$ and $y$ direction. Due to the realistic assumptions $D_{x} \gg D_{s x}, D_{y} \gg D_{s y}$, and introduced notation $K_{s}+K_{s p x}+K_{B x} \approx K_{x}, K_{s}+K_{s p y}+$ $K_{B y} \approx K_{y}$, the model (1) can be reduced to the following form, where shaft damping is neglected:

$$
\begin{aligned}
& M \ddot{x}+M_{f x}\left(\ddot{x}+2 \lambda_{x} \Omega \dot{y}-\lambda_{x}^{2} \Omega^{2} x\right)+D_{x}\left(\dot{x}+\lambda_{x} \Omega y\right)+K_{x} x \\
& =f_{x} \\
& M \ddot{y}+M_{f y}\left(\ddot{y}-2 \lambda_{y} \Omega \dot{x}-\lambda_{y}^{2} \Omega^{2} y\right)+D_{y}\left(\dot{y}-\lambda_{y} \Omega x\right)+K_{y} y \\
& =f_{y}
\end{aligned}
$$

The model (2) can be rewritten in the matrix form:

$$
\begin{aligned}
& {\left[\begin{array}{cc}
M+M_{f x} & 0 \\
0 & M+M_{f y}
\end{array}\right]\left[\begin{array}{l}
\ddot{x} \\
\ddot{y}
\end{array}\right]+\left[\begin{array}{cc}
D_{x} & 2 M_{f x} \lambda_{x} \Omega \\
-2 M_{f y} \lambda_{y} \Omega & D_{y}
\end{array}\right]} \\
& {\left[\begin{array}{c}
\dot{x} \\
\dot{y}
\end{array}\right]+\left[\begin{array}{cc}
K_{x}-M_{f x} \lambda_{x}^{2} \Omega^{2} & D_{x} \lambda_{x} \Omega \\
-D_{y} \lambda_{y} \Omega & K_{y}-M_{f y} \lambda_{y}^{2} \Omega^{2}
\end{array}\right]\left[\begin{array}{l}
x \\
y
\end{array}\right]=\left[\begin{array}{l}
f_{x} \\
f_{y}
\end{array}\right]}
\end{aligned}
$$

When the perturbation circular forces $f_{x f}, f_{y f}, f_{x b}, f_{y b}$ are applied to the system $(f=$ perturbation forward, $b=$ 
backward), the rotor lateral displacements for forward, $x_{f}, y_{f}$ and backward, $x_{b}, y_{b}$, perturbation are:

$$
\begin{gathered}
x_{f}=A_{x f} \cos \left(\omega t+\alpha_{x f}\right), y_{f}=A_{y f} \cos \left(\omega t+\alpha_{y f}\right) \\
x_{b}=A_{x b} \cos \left(\omega t-\alpha_{x b}\right), y_{b}=A_{y b} \cos \left(\omega t-\alpha_{y b}\right) \\
f_{x f}=F \cos (\omega t+\delta), f_{y f}=F \sin (\omega t+\delta) \\
f_{x b}=F \cos (\omega t-\delta), f_{y b}=-F \sin (\omega t-\delta)
\end{gathered}
$$

where $A, \alpha, F=m r \omega^{2}, \delta$ are response amplitudes and phases, unbalance perturbation force amplitudes and angular orientations, respectively. Substituting (4), (5) into Eq. (3) separately for forward and backward perturbation cases yields identification equations for each direction:

$$
[\kappa][A]_{f}=[f]_{f},[\kappa][A]_{b}=[f]_{b}
$$

where $\kappa$ is the complex dynamic stiffness matrix and

$$
\begin{aligned}
& {[A]_{f}=\left[\begin{array}{l}
A_{x f} e^{j \alpha_{x f}} \\
A_{y f} e^{j \alpha_{x f}}
\end{array}\right],[A]_{b}=\left[\begin{array}{l}
A_{x b} e^{j \alpha_{b f}} \\
A_{y b} e^{j \alpha_{x b}}
\end{array}\right],} \\
& {[f]_{f}=\left[\begin{array}{c}
F e^{j \delta} \\
-j F e^{j \delta}
\end{array}\right],[f]_{b}=\left[\begin{array}{c}
F e^{-j \delta} \\
j F e^{-j \delta}
\end{array}\right]} \\
& {[\kappa]=\left[\begin{array}{ll}
\kappa_{11} & \kappa_{12} \\
\kappa_{21} & \kappa_{22}
\end{array}\right]} \\
& \equiv\left[\begin{array}{c}
K_{x}-\left(M+M_{f x}\right) \omega^{2}-M_{f_{x}} \lambda_{x}^{2} \Omega^{2}+j D_{x} \omega \\
-D_{y} \lambda_{y} \Omega-j 2 M_{f_{y}} \lambda_{y} \Omega \omega
\end{array}\right. \\
& \left.\begin{array}{c}
D_{x} \lambda_{x} \Omega+j 2 M_{f x} \lambda_{x} \Omega \omega \\
K_{y}-\left(M+M_{f y}\right) \omega^{2}-M_{f y} \lambda_{y}^{2} \Omega^{2}+j D_{y} \omega
\end{array}\right]
\end{aligned}
$$

Each complex dynamic stiffness component, $\kappa_{i j}$, splits into direct (real) and quadrature (imaginary) parts. Combining the results of the forward and backward cases (6) and inverting the response vector matrix, the following anisotropic system complex dynamic stiffness matrix equation is obtained:

$$
[\kappa]=\left[\begin{array}{cc}
F e^{j \delta} & F e^{-j \delta} \\
-j F e^{j \delta} j F e^{-j \delta}
\end{array}\right]\left[\begin{array}{l}
A_{x} e^{j \alpha_{x f}} A_{x b} e^{-j \alpha_{x b}} \\
A_{y} e^{j \alpha_{x f}} A_{y b} e^{-j \alpha_{y b}}
\end{array}\right]^{-1}
$$

For a given $\Omega$ from $\kappa_{11}$, the following parameters can be identified: $K_{x}-M_{f x} \lambda_{x}^{2} \Omega^{2}, D_{x}$ and $M+M_{f x}$; from $\kappa_{12}$ : $M_{f x}$ and $\lambda_{x}$ can be identified; from $\kappa_{21}: M_{f y}$ and $\lambda_{y}$; from $\kappa_{22}: \mathrm{K}_{\mathrm{y}}-\mathrm{M}_{\mathrm{fy}} \lambda_{y}^{2} \Omega^{2}, D_{y}$ and $M+M_{f y}$ respectively can be identified. Eq. (9) yields a matrix of system dynamic stiffnesses for each perturbation frequency, $\omega$. Frequency swept perturbation and the combination with forward and backward results in the matrix of dynamic stiffnesses as functions of $\omega$ which can be used for further parameter identification. Where $\omega$ is vary from zero to a specified speed covering the range of natural frequency of the system.

\section{TEST RIG}

The test rig is shown in Figure 1. The rotor system is comprised of a stainless steel shaft, $0.01 \mathrm{~m}$ in diameter and $0.47 \mathrm{~m}$ in length, with a journal of $0.025 \mathrm{~m}$ diameter and $406 \mu \mathrm{m}$ diametral clearance inside the fluid-lubricated bearing, and a rigid coupling half component (used in another experiment). The motor end of the shaft is supported on a radially-rigid pivoting rolling element bearing, and the other end by a 'Chevron GST Oil 32' turbine-oil lubricated bearing. This fluid lubricated bearing has four equally spaced oil inputs and inlet/outlet oil temperatures are monitored by two thermocouples those are located inlet/outlet oil supply tubes of the fluid lubricated bearing. To control the oil temperature, a water bath heat exchanger is used between the oil pump and the bearing inlet. Oil temperature is controlled to $21^{\circ} \mathrm{C} \pm 1.5^{\circ} \mathrm{C}$. Four $3100 \mathrm{~N} / \mathrm{m}$ stiffness radial supporting springs mounted in a frame near the fluid film bearing control the journal eccentricity. One pair of XY eddy current displacement probes is mounted 45 degrees left and 45 degrees right from the vertical axis in the fluid-lubricated bearing to obtain rotor lateral vibration data. The main rotor is driven by a bi-directional $75 \mathrm{~W}$ motor, installed at left end.

The perturbation system consists of an aluminum disk connected through a soft rubber drive belt to the main

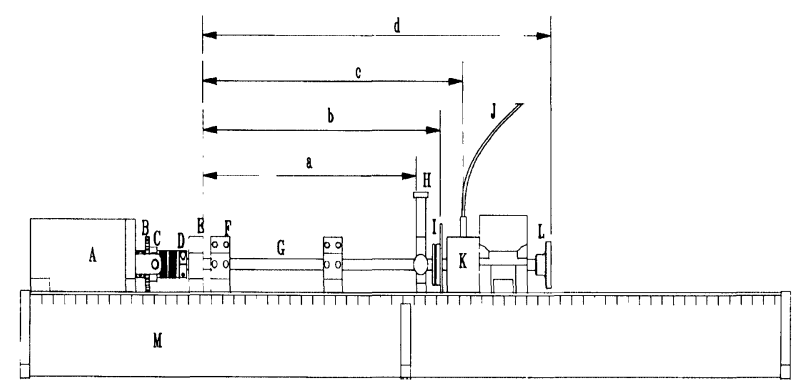

FIGURE 1 Experimental Test Rig $[\mathrm{a}=0.28 \mathrm{~m}, \mathrm{~b}=0.32 \mathrm{~m}, \mathrm{c}=$ $0.36 \mathrm{~m}, \mathrm{~d}=0.47 \mathrm{~m}$ ] A) 75 watt electric motor, B) Speed Control Probe, C) Keyphasor Tansducer (rotor), D) Flexible Motor Coupling, E) Rolling Element Bearing, F) Probe Mounting Block, G) Rotor, H) Supporting Spring Frame, I) Perturbation Disk, J) Probe Mounted at Fluid-Lubricated Bearing, K) Fluid-Lubricated Bearing, L) Rigid Coupling Half Component, M) V-shape Base. 
rotor system perturbator wheel carrying a known unbalance weight. It is driven by a motor similar to the main rotor. The perturbation system is installed behind the perturbation disk. This type of system allows for nonsynchronous shaft perturbation in forward and backward directions by using unbalance-induced circular rotating force, swept frequency perturbation which is entirely independent from the rotative speed of the main rotor. The rotor response excited by the perturbator is captured by the data acquisition system and then filtered to the perturbation frequency. The response phase is measured using an optical Keyphasor ${ }^{\circledR}$ transducer that observes a reflective spot on the side of the perturbation wheel. To compensate phase measurement change between forward and backward precession, response phase of backward precession was adjusted by $3^{\circ}$. This accounts for the width of the Keyphasor notch on the shaft. A digital vector filter and data processing software were used in the test.

The tests were performed for the following conditions: The fluid bearing is a four radial port bearing. The oil supply pressure at the radial manifold was maintained at approximately $18 \mathrm{kPa}$. The constant rotative speed of the rotor, $\Omega$, was $0,1000,2000,3000 \mathrm{rpm}$. Nonsynchronous perturbation runs from $260 \mathrm{rpm}$ to $2300 \mathrm{rpm}$ were performed for each rotative speed. The results from the $2000 \mathrm{rpm}$ rotative speed case are presented here. Rotor responses, to 3.1 gram unbalance weight for the forward, and 3.1 (Case 1) and 20.1 gram (Case 2) for backward perturbation were selected through the several tests. The unbalance weights were installed in line with vertical probe location. The perturbation disk, with $0.035 \mathrm{~m}$ radius of unbalance, was used for these known unbalance masses. In order to maximize the data's signal-to-noise ratio, differential data technique (Franklin et al [1994]) was used.

\section{TESTS RESULTS}

The rig was designed to have a conical rigid body mode of the rotor within the nonsynchronous perturbation speed range. Through the basic tests, the quadrature (fluid-induced) resonance speeds were found at about $500,970,1460 \mathrm{rpm}$ for $1000,2000,3000 \mathrm{rpm}$ rotative speed respectively. These results show that the system resonance is fluid-related, and the viscous damping of the fluid film is its dominant characteristic. The damping in the fluid film has an over-critical value (Muszynska and Bently [1995]) and high damping ratio (about 10).

Table 1 summarizes the identified rotor/fluid bearing system parameters at $2000 \mathrm{rpm}$ operating speed condition. They were obtained based on the algorithm (8). The dynamic stiffness plots are shown in Figure 2. A polynomial curve fitting was used to obtain rotor system modal parameters from the plots. Two different conditions, Case 1 and Case 2, were tested. When using the same unbalance weight for both forward and backward perturbation, the magnitude of backward perturbation response amplitude is much smaller than that of forward perturbation (Case 1). In the Case 2, the backward perturbation force was 6.5 times higher. Two cases were, therefore, tested to verify and to compare the results from backward precession (unbalance weights: 3.1 gram and 20.1 gram). In Figure 2, the direct and quadrature stiffness plots present the expected results described by the algorithm (8). They illustrate anisotropic components, which are mainly included in the direct stiffnesses of $\kappa_{11}$ and $\kappa_{22}$, and the quadrature stiffnesses of $\kappa_{12}$ and $\kappa_{21}$, when the journal was positioned at low eccentricity ratio, about 0.1 , near the bearing center. Since it was difficult to separate $M$ and $M_{f}, M$ was calculated separately by considering rotor physical dimensions and steel density, $7.86 \times 10^{3} \mathrm{~kg} / \mathrm{m}^{3}$.

Figures 3 to 5 and 9 (a) present the experimental response data in the Bode and polar plot formats for several cases. There is some disturbance in the data when the perturbation and rotation frequency are equal, around $2000 \mathrm{rpm}$, which is due to an interference in the filtering system. For the forward perturbation there is a high peak resonance (fluid-induced or quadrature resonance). In each case, there can also be seen the existence a resonance for backward perturbation, which has been previously undocumented. This resonance amplitude is

TABLE 1

Identified Parameters of the Rotor/Fluid Lubricated Bearing System $(\Omega=2,000 \mathrm{rpm})$.

\begin{tabular}{lllllllll}
\hline & $D_{x}$ & $D_{y}$ & $\lambda_{x}$ & $\lambda_{y}$ & $M_{f x}$ & $M_{f y}$ & $K_{x}$ & $K_{y}$ \\
\hline unit & $\mathrm{kg} / \mathrm{s}$ & $\mathrm{kg} / \mathrm{s}$ & & & $\mathrm{kg}$ & $\mathrm{kg}$ & $\mathrm{kN} / \mathrm{m}$ & $\mathrm{kN} / \mathrm{m}$ \\
Case 1 & $2.16 \times 10^{3}$ & $2.17 \times 10^{3}$ & 0.477 & 0.474 & 0.22 & 0.49 & 5.25 & 29.40 \\
Case 2 & $2.14 \times 10^{3}$ & $2.15 \times 10^{3}$ & 0.473 & 0.470 & 0.10 & 0.27 & 4.21 & 30.30 \\
Case 3 & $2.24 \times 10^{3}$ & $2.10 \times 10^{3}$ & 0.429 & 0.519 & 0.24 & 0.49 & 17.15 & 17.98 \\
\hline
\end{tabular}

Case 1: 3.1 gram for forward and backward perturbation test was used.

Case 2: 3.1 gram for forward, and 20.1 gram for backward perturbation test were used.

Case $3:-45^{\circ}$ coordinate rotation was applied to the Case 1 results. 
(a) $\kappa_{11}=K_{x}-\left(M+M_{f x}\right) \omega^{2}-M_{f x} \lambda_{x}^{2} \Omega^{2}+j D_{x} \omega$
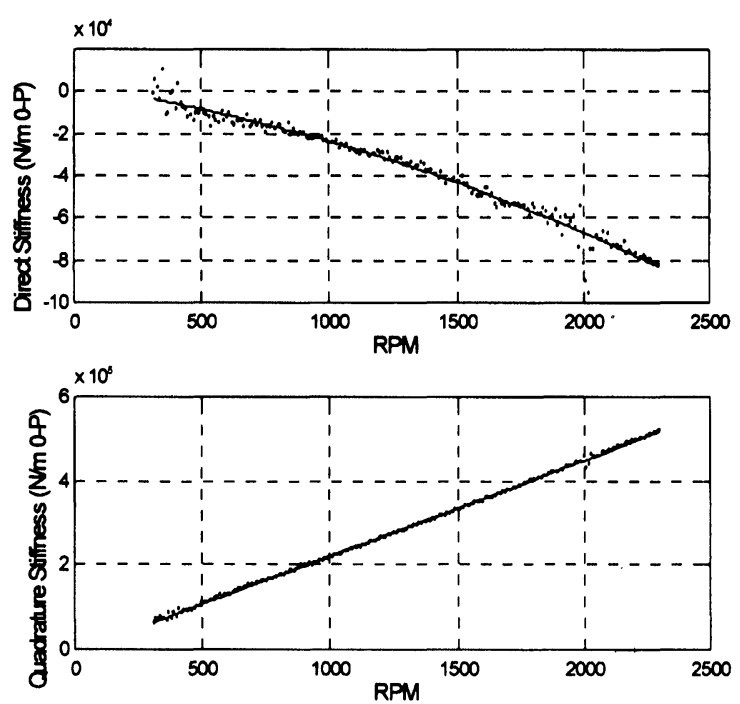

(c) $\kappa_{21}=-D_{y} \lambda_{y} \Omega-j 2 M_{f y} \lambda_{y} \Omega \omega$
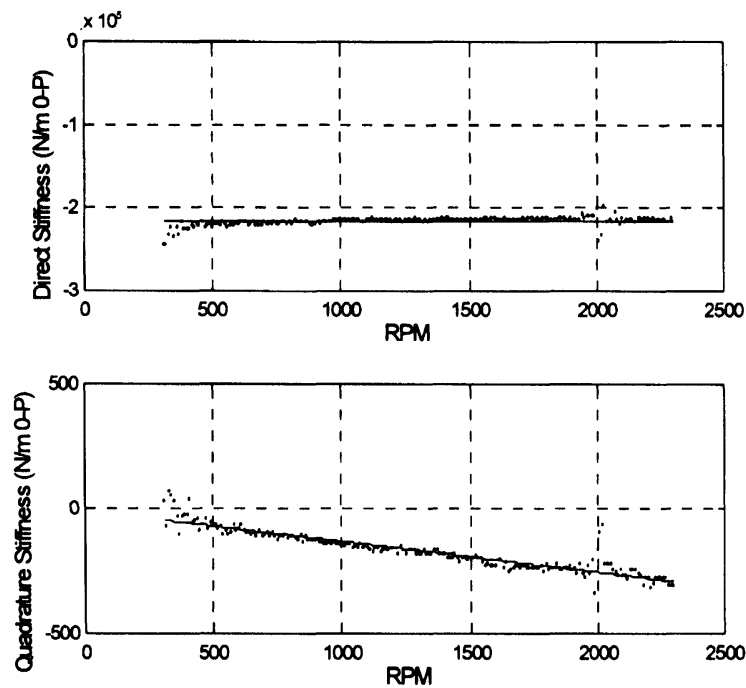

(b) $\kappa_{12}=D_{x} \lambda_{x} \Omega+j 2 M_{f x} \lambda_{x} \Omega \omega$
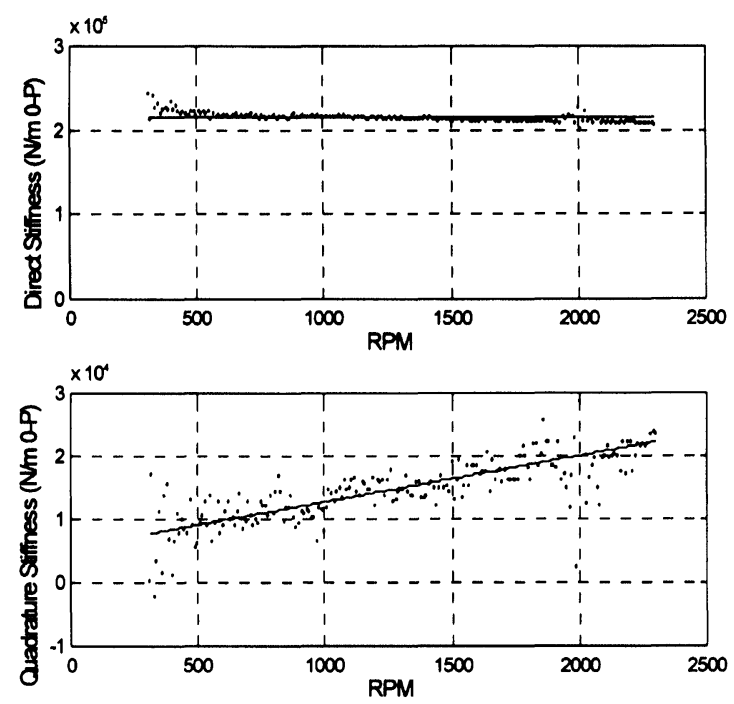

(d) $\kappa_{2}=K_{y}-\left(M+M_{f y}\right) \omega^{2}-M_{f y} \lambda_{y}^{2} \Omega^{2}+j D_{y} \omega$
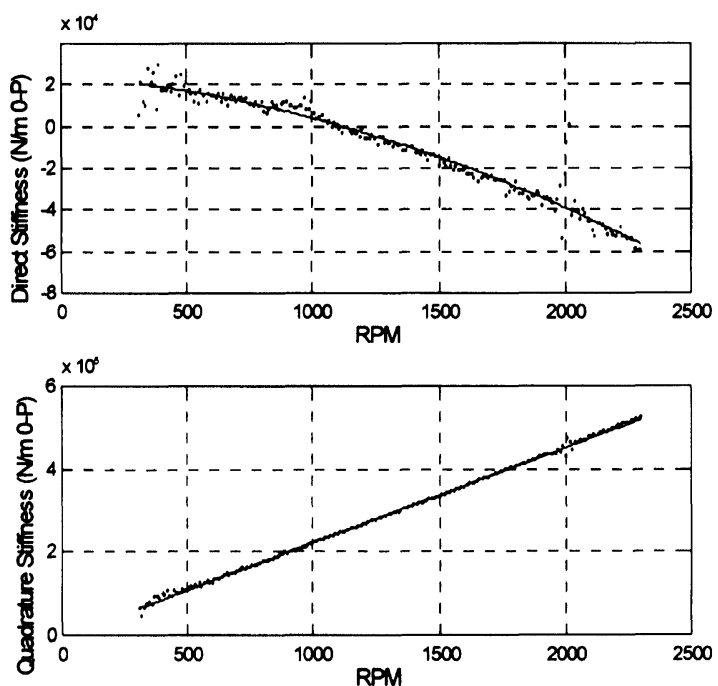

FIGURE 2 A Matrix of Complex Dynamic Stiffness Plots of the Rotor/Fluid Bearing Response with Anisotropy Algorithm for Case 1: 3.1g for forward and backward perturbation test was used. Compare with Eq.(8). [Solid Line: polynomial fitting curve, Dot: experimental data, $\Omega=2000$ rpm].

much smaller than the one for the forward perturbation. When the phase and amplitude pattern near $970 \mathrm{rpm}$ is considered, it seems to be fluctuating due to a residual effect of the forward rotating rotor rather than a resonance. But the analytically calculated data based on Eq. (6) and presented in Figures 6-8 and 9(b) show the same patterns as the experimental data. The comparison of the result from Case 1 with the result of signal-to-noise ratio enhancement data indicate that (Case 2) the results in Fig. 4 present the same response pattern as in Figure 3. From here, it can be concluded that the observed phenomenon is a resonance due to anisotropy. According to 
(a) Experimental backward response

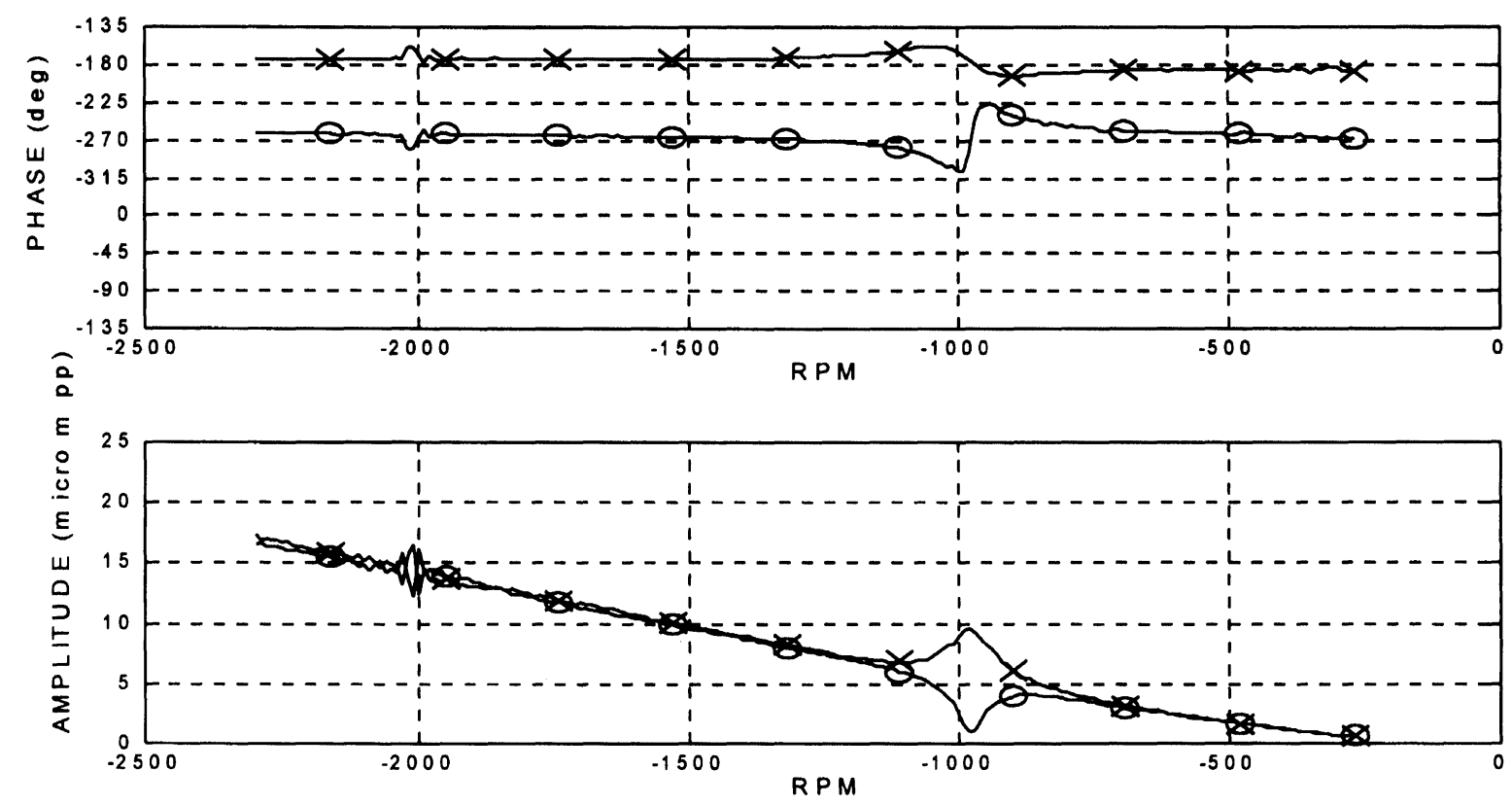

(b) Experimental forward response
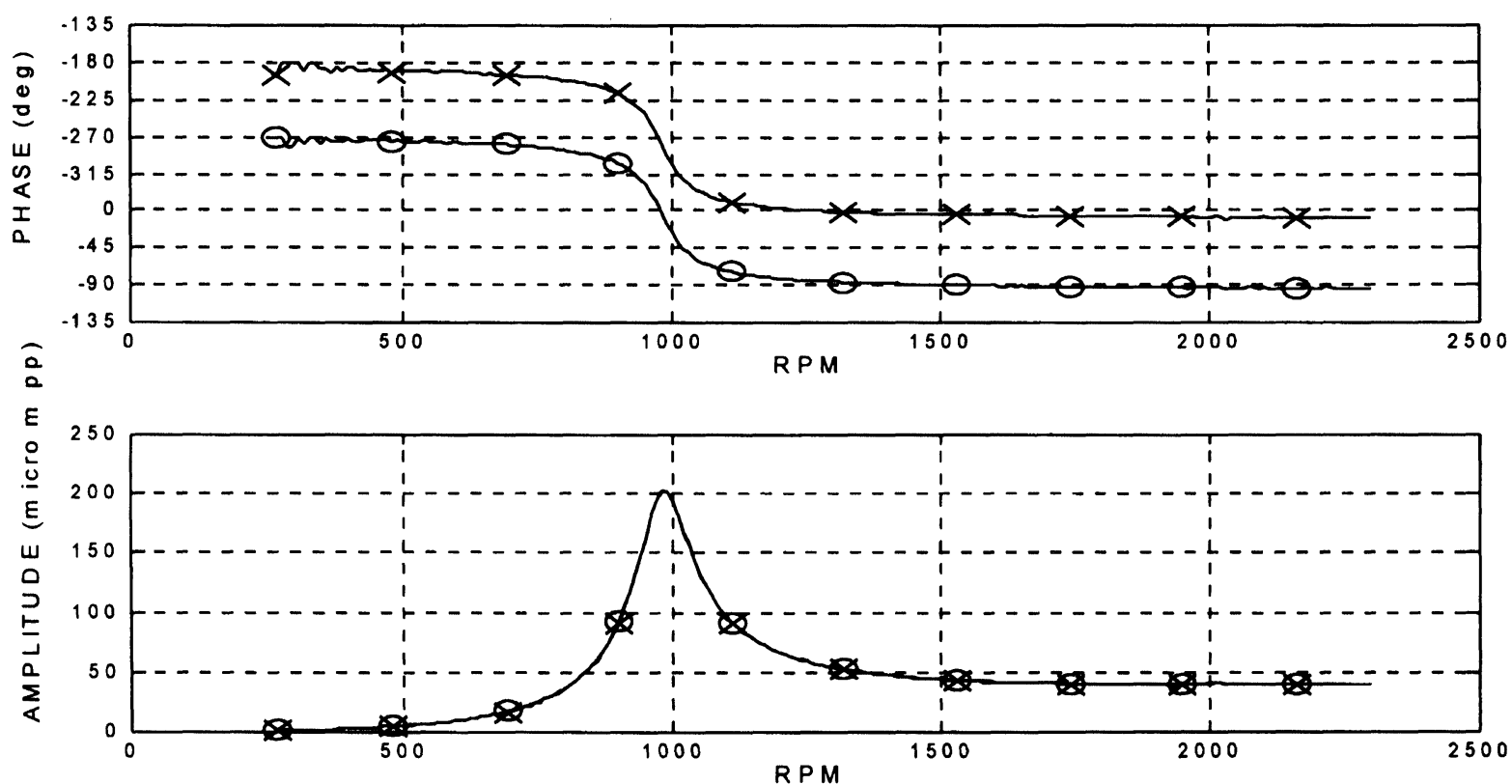

FIGURE 3 Bode Plots of Rotor Amplitudes and Phases versus Perturbation Frequency for Case 1: $3.1 \mathrm{~g}$ for forward and backward perturbation test was used. (Note different amplitude scales for the forward and backward perturbations). The forward perturbation response does not show any effect of anisotropy. [ $\Omega=2000 \mathrm{rpm}$, x: horizontal (x probe) response, o: vertical (y probe) response]

the identified parameters in Table 1 , the system has anisotropic stiffness and fluid inertia. To consider other parameter's anisotropy condition, the coordinate transformation to rotate the axes was applied to Case 1. Case 
(a) Experimental backward response

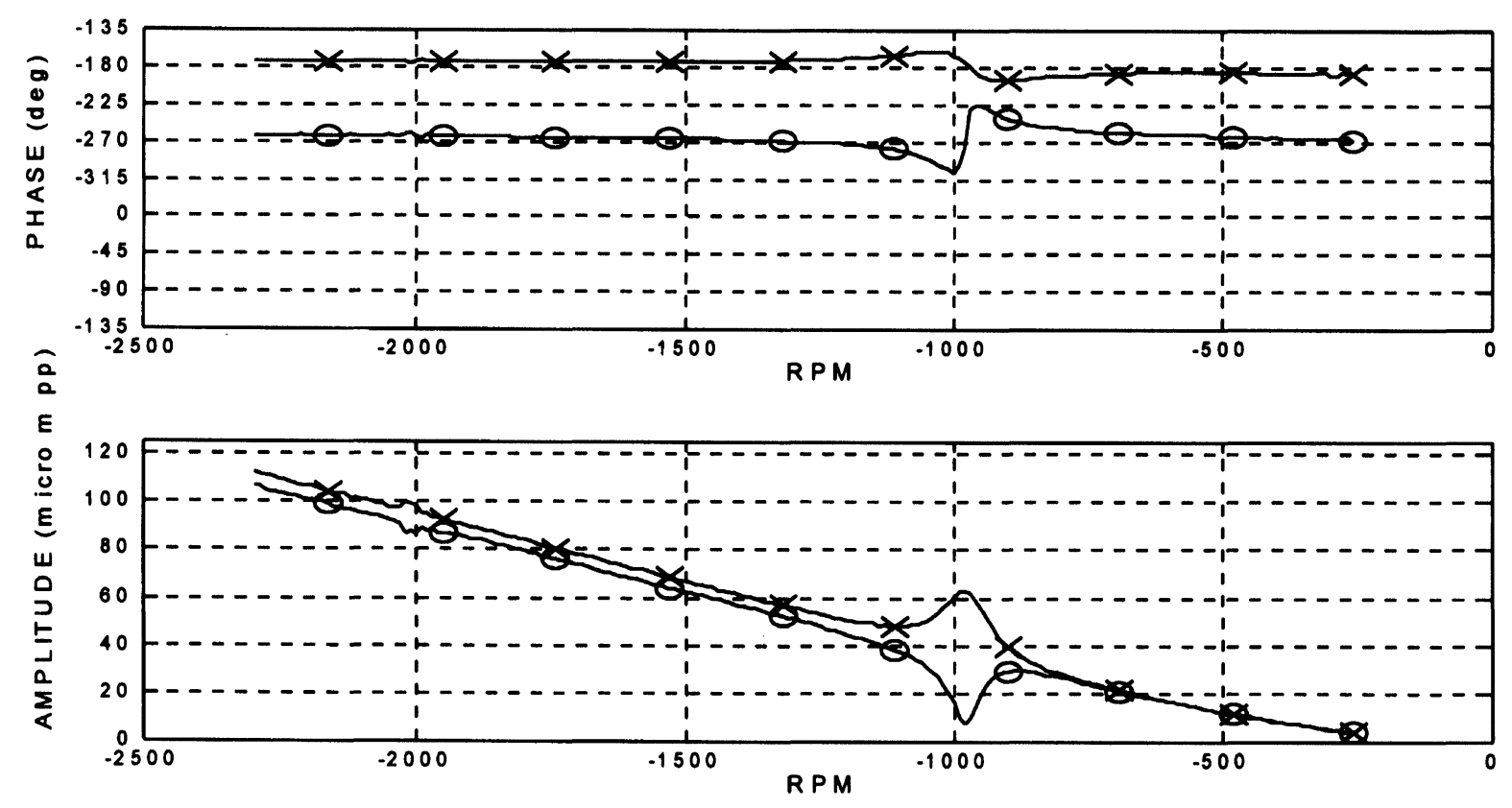

(b) Experimental forward response
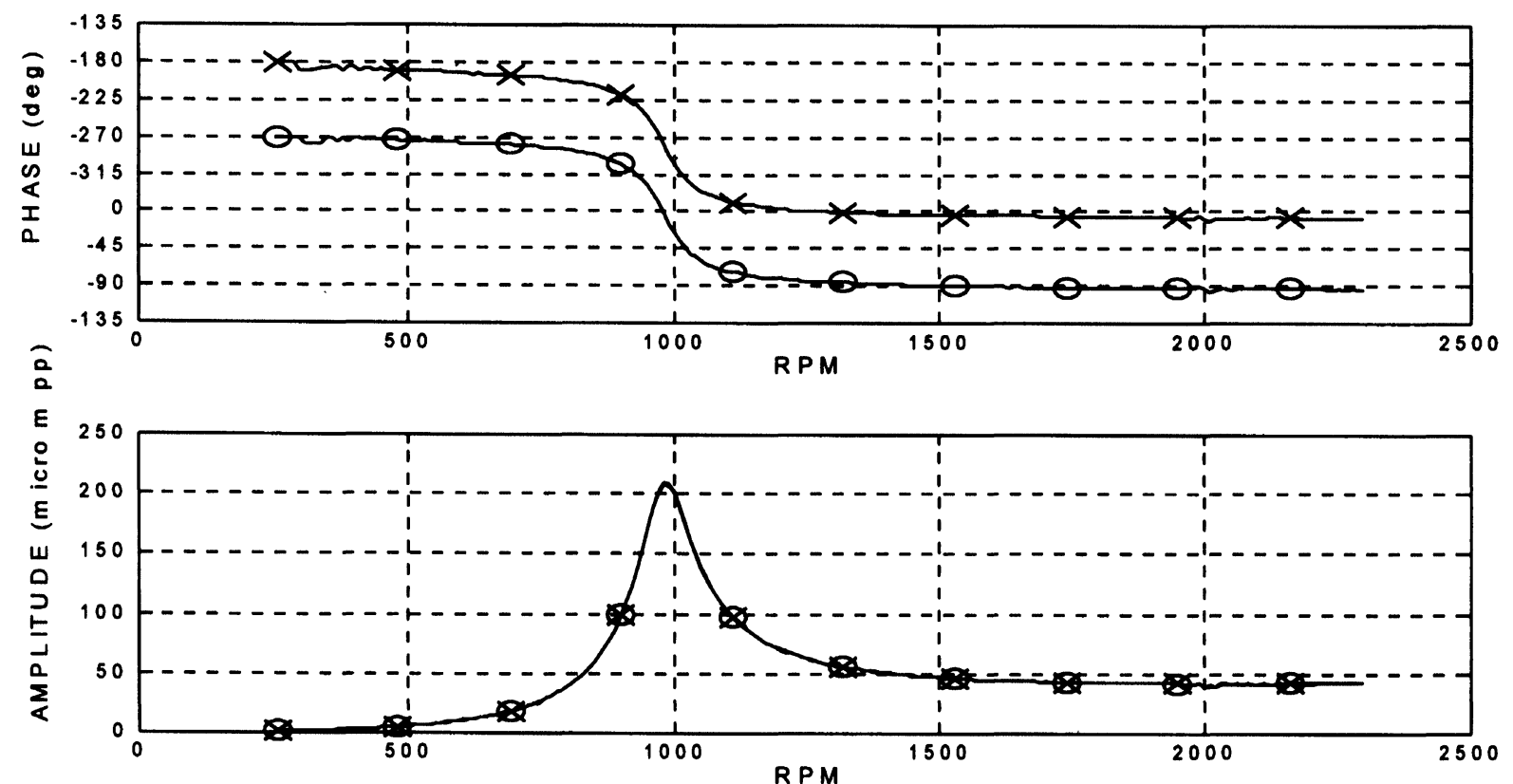

FIGURE 4 Bode Plots of Rotor Amplitudes and Phases versus Perturbation Frequency for Case 2: $3.1 \mathrm{~g}$ for forward, and $20.1 \mathrm{~g}$ for backward perturbation test were used. (Now there is less difference in amplitude scales). The backward resonance pattern remain the same as in Figure 3. $[\Omega=2000 \mathrm{rpm}, \mathrm{x}$ : horizontal (x probe) response, o: vertical (y probe) response]

3 shows the results in which the stiffness $K_{x}$ and $K_{y}$ are almost equal. The resonance phenomenon still exists, but the shape of it has been changed. The parameters in Case 3 show that the dominant anisotropy in this case are 
(a) Experimental backward response

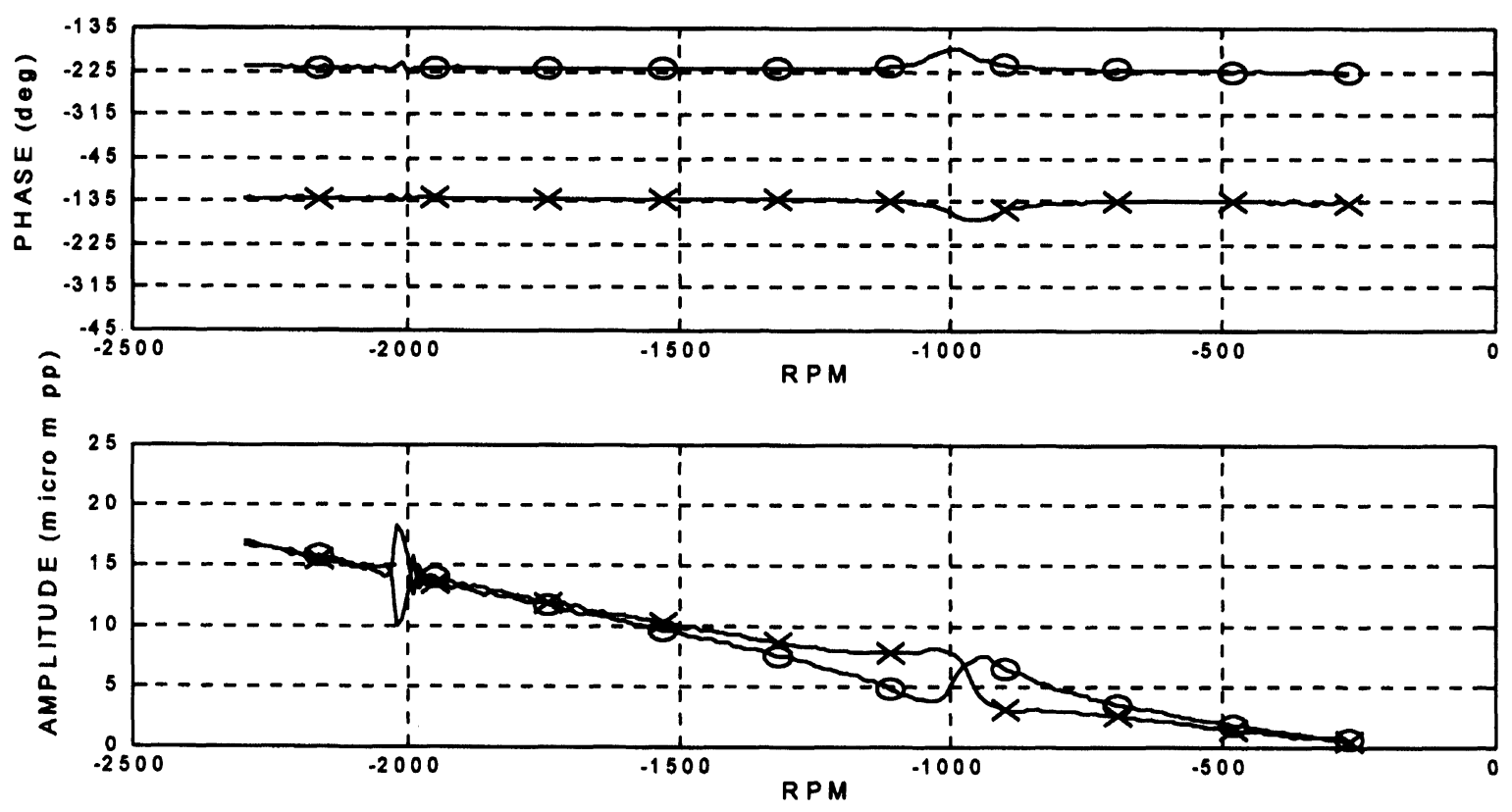

(b) Experimental forward response
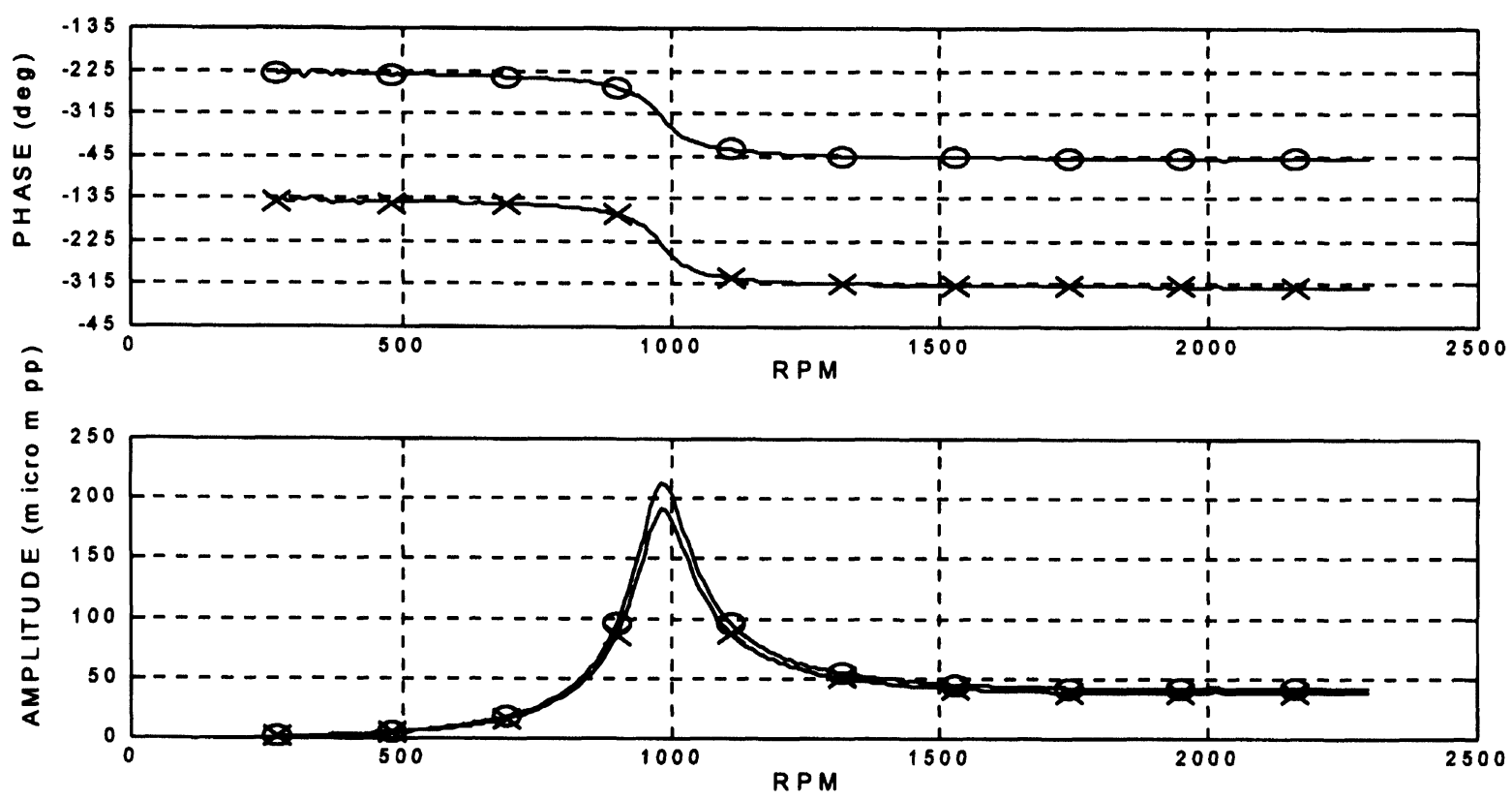

FIGURE 5 Bode Plots of Rotor Amplitudes and Phases versus Perturbation Frequency for Case 3: $-45^{\circ}$ coordinate rotation was applied to the Case 1 results. A slight difference in forward amplitude data is observed. $[\Omega=2000 \mathrm{rpm}$, $\mathrm{x}$ : horizontal (x probe) response, o: vertical (y probe) response] 
(a) Analytical backward response

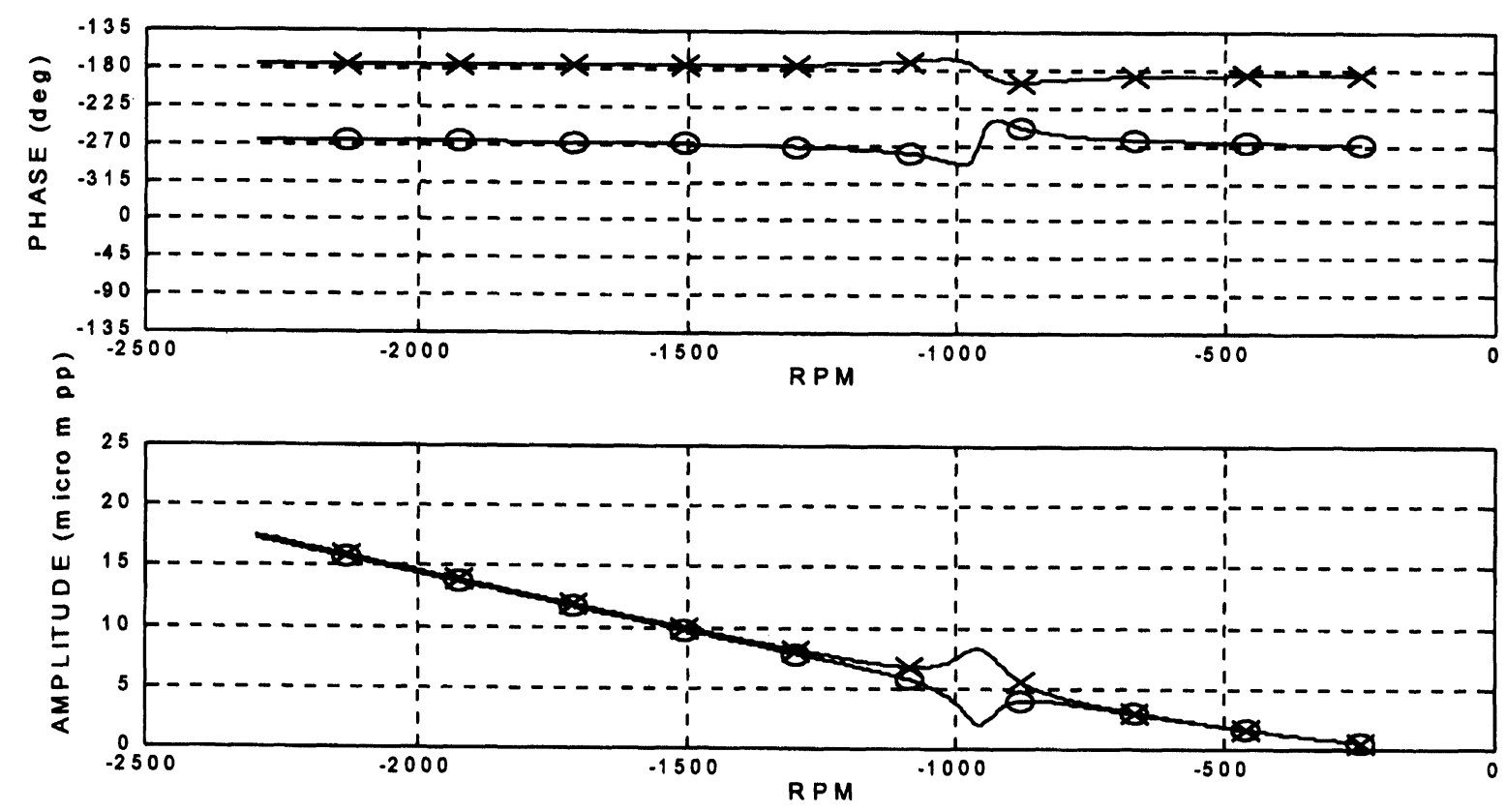

(b) Analytical forward response
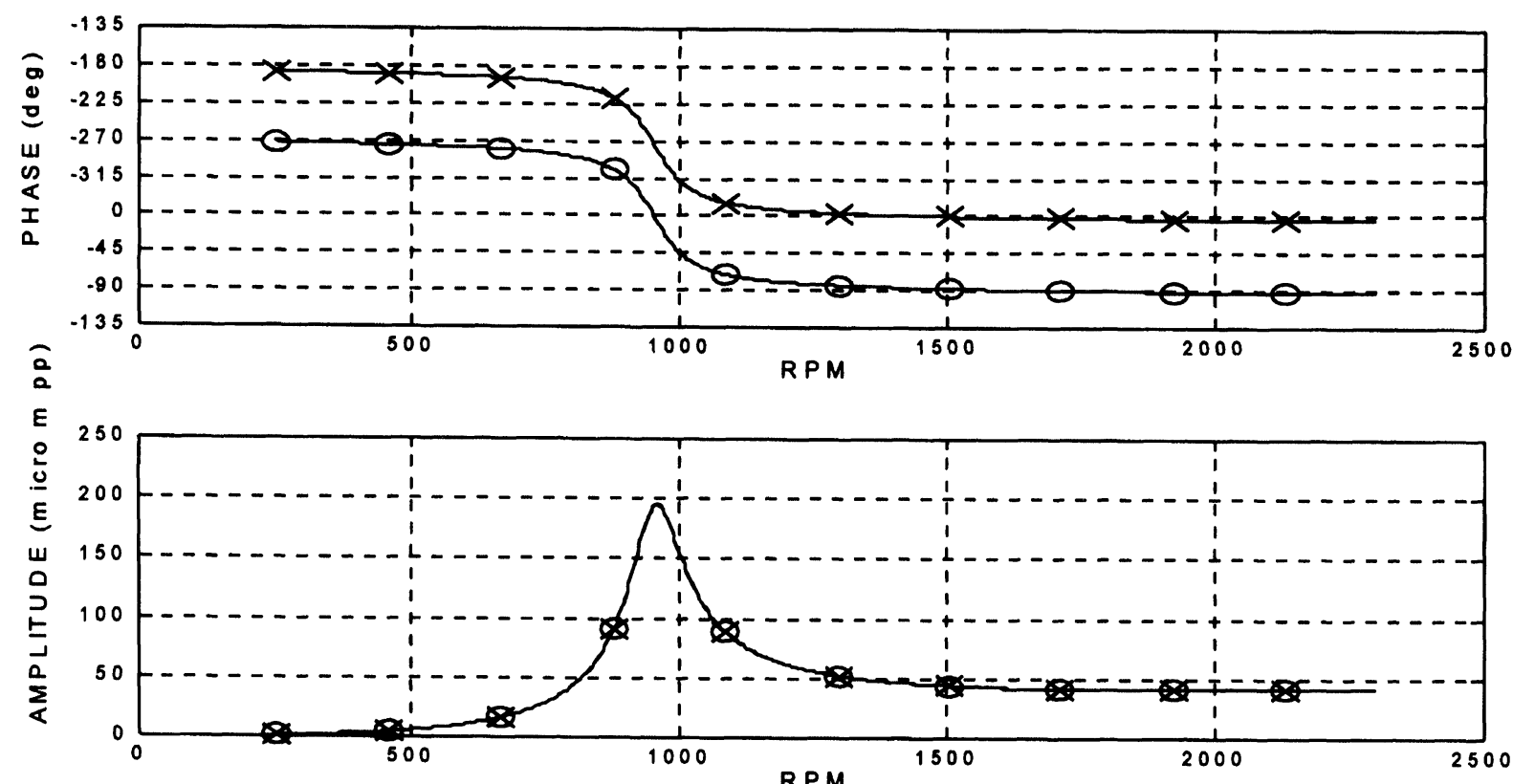

FIGURE 6 Bode Plots of Rotor Amplitudes and Phases versus Perturbation Frequency for Case 1: 3.1 gram for forward and backward perturbation test was used. Calculated analytically using identified parameters from Table 1 . $[\Omega=2000 \mathrm{rpm}$, x: horizontal (x probe) response, o: vertical (y probe) response] 
(a) Analytical backward response

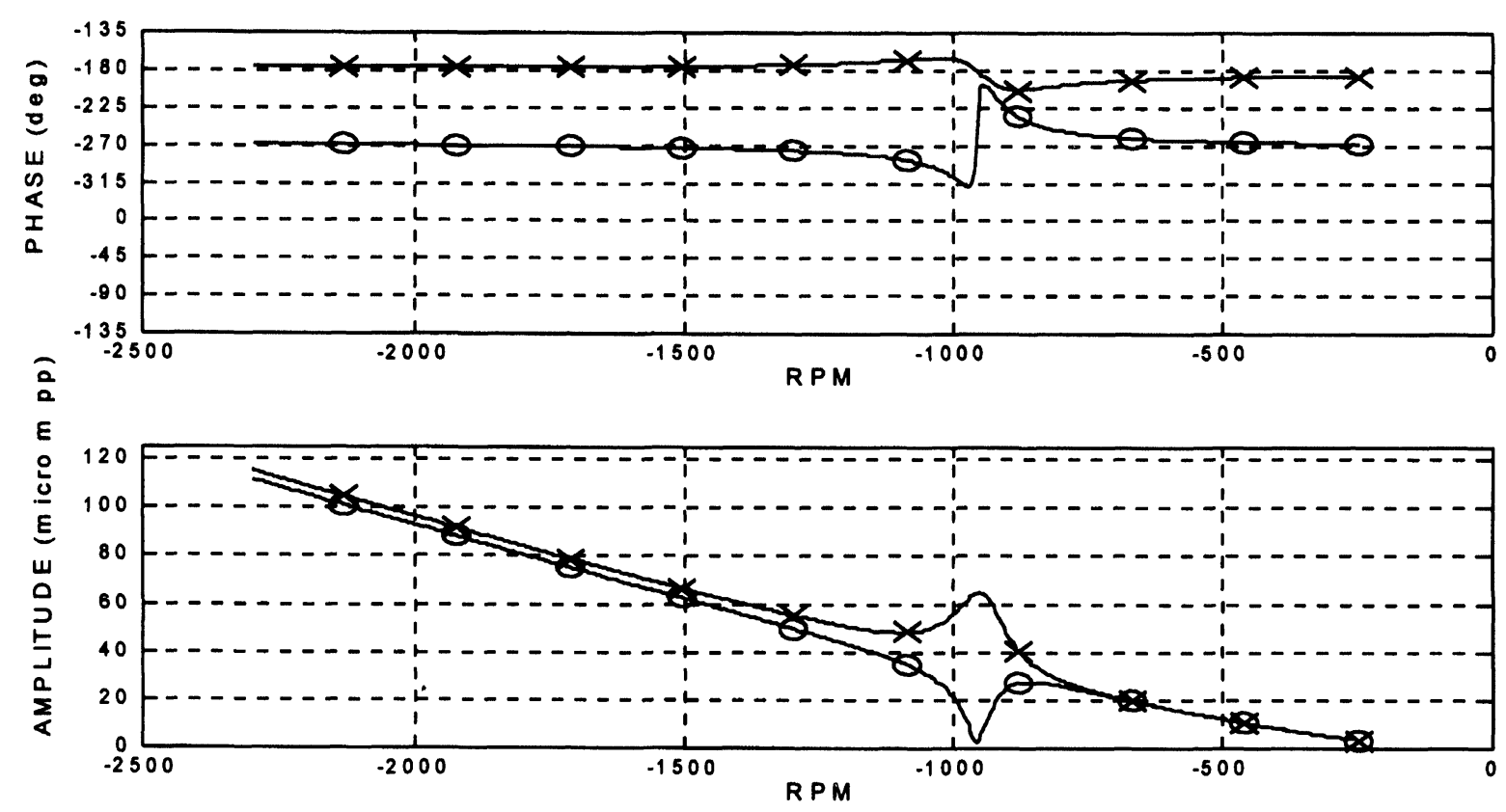

(b) Analytical forward response
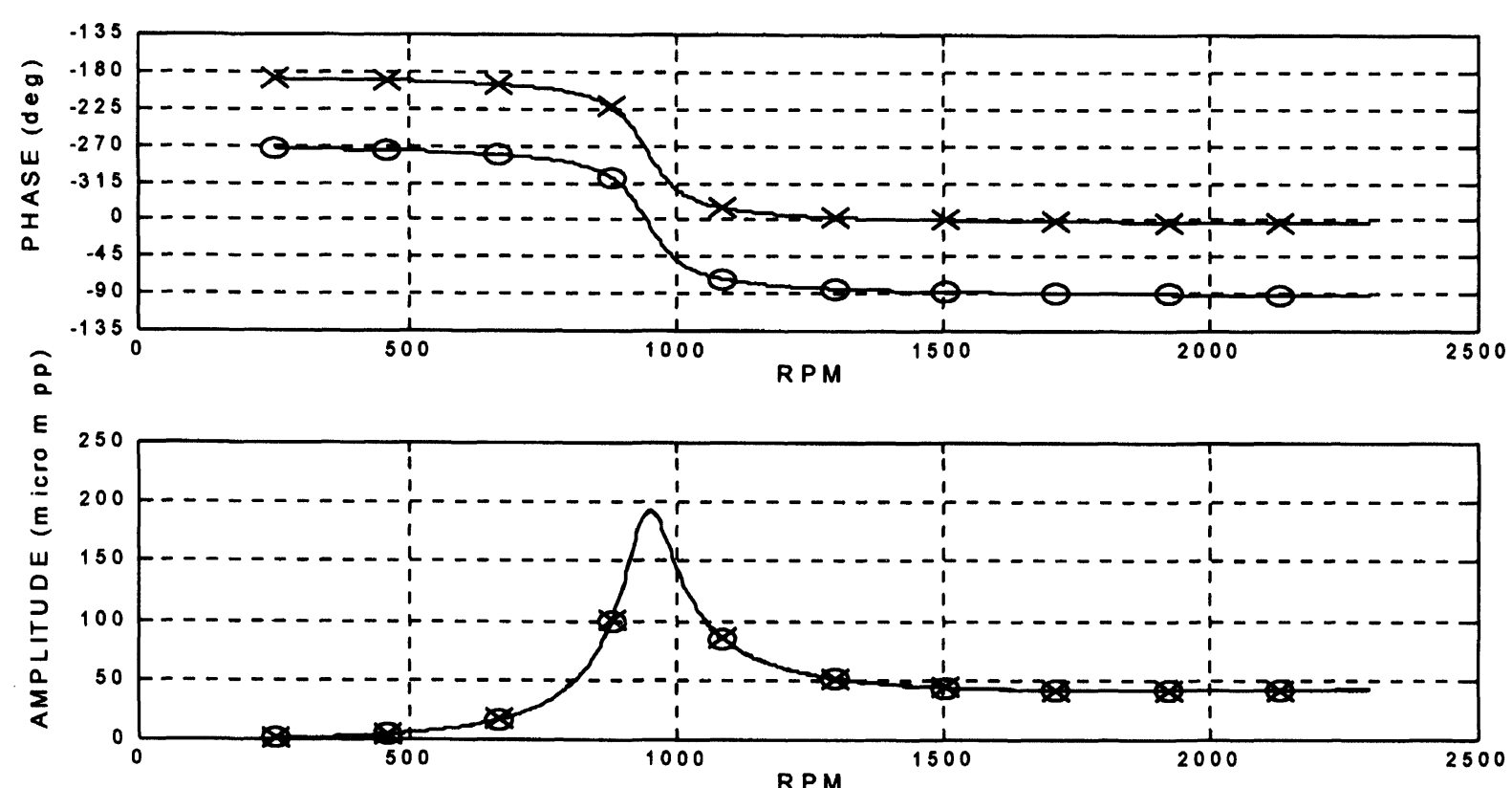

FIGURE 7 Bode Plots of Rotor Amplitudes and Phases verşus Perturbation Frequency for Case 2: $3.1 \mathrm{~g}$ for forward, and $20.1 \mathrm{~g}$ for backward perturbation test were used. Data calculated analytically using identified paramters from Table 1. [ $\omega=2000 \mathrm{rpm}, \mathrm{x}$ : horizontal (x probe) response, o: vertical (y probe) response] 
(a) Analytical backward response
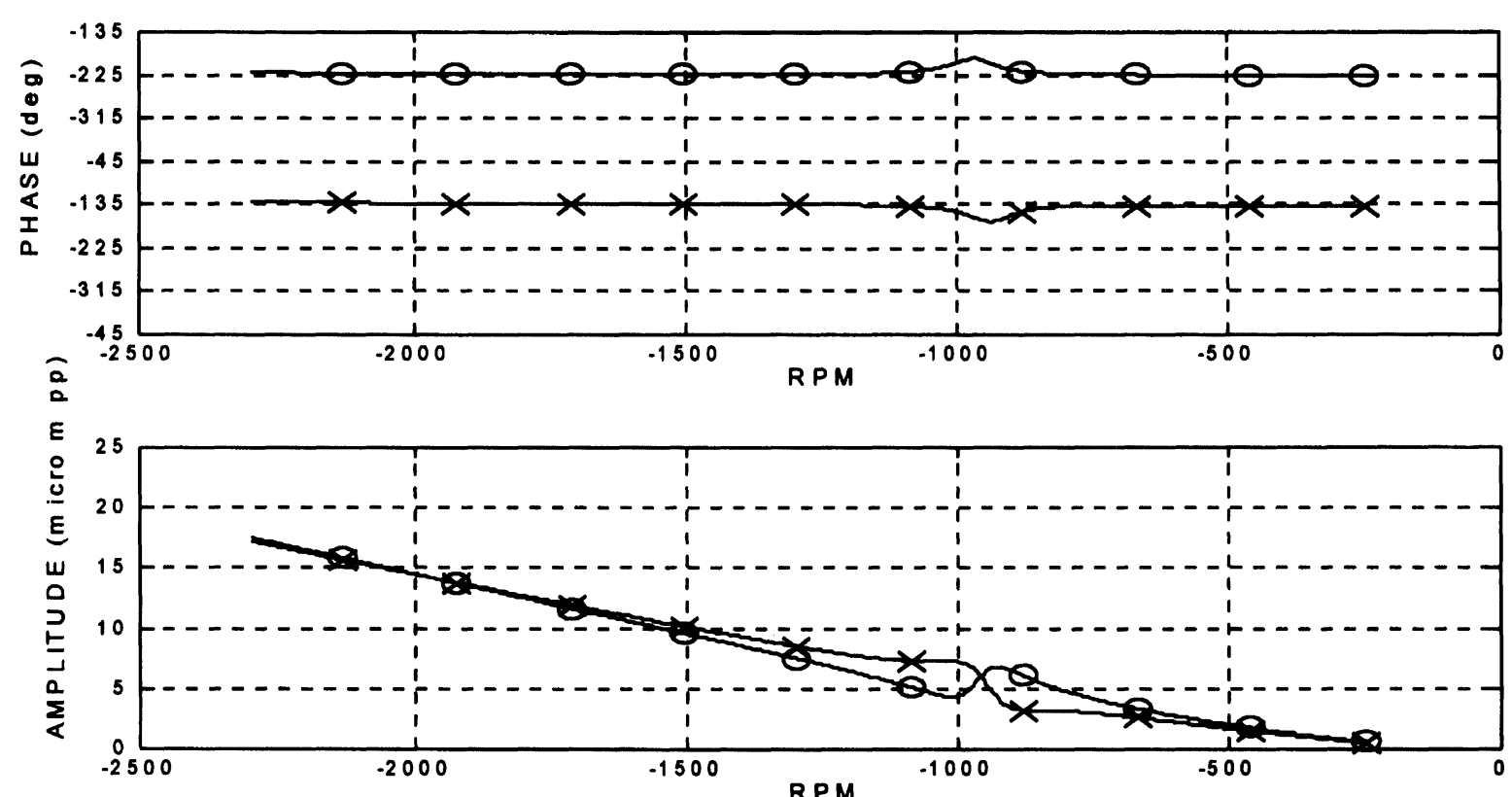

(b) Analytical forward response
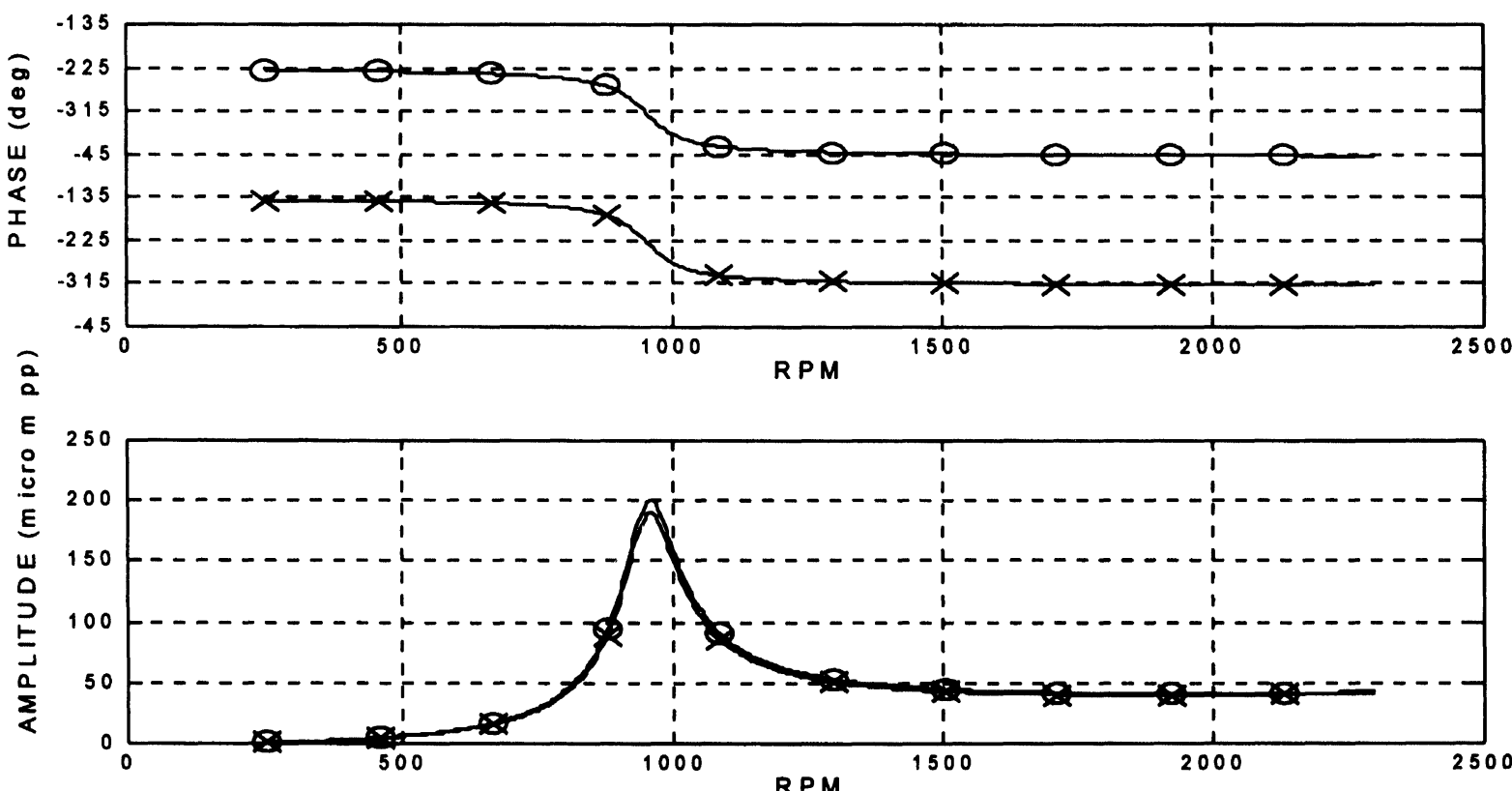

FIGURE 8 Bode Plots of Rotor Amplitudes and Phases versus Perturbation Frequency for Case 3: $-45^{\circ}$ coordinate rotation was applied to the Case 1 analytical results. Data calculated analytically using identified parameters from Table 1. [ $\omega=2000 \mathrm{rpm}$, $\mathrm{x}$ : horizontal (x probe) response, o: vertical (y probe) response] 
(a)
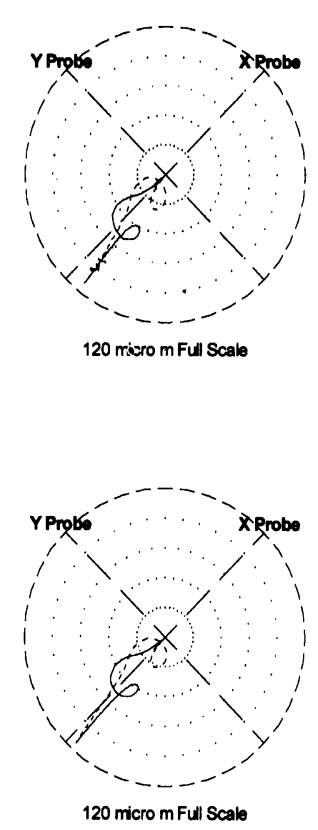

(b)
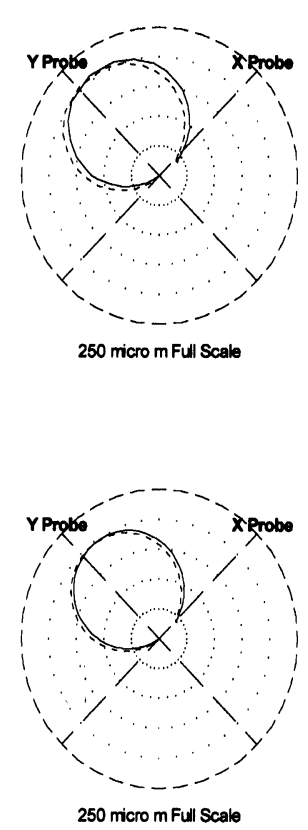

FIGURE 9 Backward (a) and Forward (b) Perturbation Response Polar Plots for experimental and analytically calculated data based on identified model parameters of Case 2: $3.1 \mathrm{~g}$ for forward, and 20.1 $\mathrm{g}$ for backward perturbation were used. [solid line: $\mathrm{x}$ probe, dash line: $\mathrm{y}$ probe].

damping and fluid circumferential average velocity ratio. Figures 6-8 present analytically calculated response in the form of Bode plots. The parameters in the model were taken from Table 1.

The comparison of Figures 6 to 8 with Figures 3 to 5 shows strong agreement of analytical and experimental responses. To understand the effect of each anisotropyparameter, several tests were applied to the analytical model program; When isotropic values are used, there is no backward precession resonance. The other cases with anisotropy of the stiffness, damping effect, fluid circumferential average velocity ratio, and fluid inertia, respectively, present the existence a resonance of backward precession. The pattern of it was changing for different kinds of anisotropy. In case of anisotropy of stiffness and fluid inertia, respectively, the results looks like plots in Figures 3 and 4 . The cases of anisotropy of damping and fluid circumferential average velocity ratio, respectively, show a similar pattern to that in Figure 5.

\section{DISCUSSION AND CONCLUSIONS}

The paper presented the low-frequency precessional behavior results of a symmetric rotor supported aniso-

tropically, and excited by nonsynchronous perturbation testing. In the analysis of rotating machinery dynamic behavior, a very important aspect is a phase information. Limiting modal testing to the lowest modes increases the accuracy of phase information. In the present results the measurement error was less than $1 \%$.

The developed dynamic stiffness identification algorithm, for two mode lateral anisotropic model with fluid interaction effects, proved to be effective for identifying the rotor/fluid bearing system through modal testing. Complex dynamic stiffness plots present the results expected from the algorithm. The analytical model results using identified parameters show very good agreement with experiment results. The application of dynamic stiffness method provides an efficient way for parameter identification. The model can be extended to consider nonlinear effects, and to include two different rates of $\lambda$, one for the fluid radial damping and another for the fluid inertia force rotation rate (Grant et al [1993]).

The paper documents a specific type of fluid-induced resonance behavior for backward precession under the anisotropy of the rotor/bearing system. It is known that the quadrature resonance (or fluid-induced resonance), which is caused by rotor/fluid interaction, occurs at one of the rotor/fluid bearing system natural frequencies, and exists only for forward direction (Bently and Muszynska [1985]). This result was obtained for isotropic conditions. In this paper, to verify whether there exists a resonance phenomenon for backward precession or not, several tests were applied to the both experimental and model data. The results present the existence of the resonance, with phase and amplitude changing pattern, only under anisotropy condition of the system. There is no backward direction resonance when isotropic parameters are used. For other operating speeds, $1000 \mathrm{rpm}$ and $3000 \mathrm{rpm}$, the same result patterns were obtained. When considering low damping, the responses show a more complex pattern, but the similar phenomenon is still present. In the test for analytical model, the backward resonance patterns change if anisotropic fluid inertia or damping parameters are respectively modified.

The discussed results describe the existence of backward quadrature resonance under anisotropy. They show different resonance response patterns according to the anisotropy parameter. The results can be used as a diagnostic tool to identify a dominant parameter, when anisotropy exists in the rotor/fluid bearing system.

Nomenclature

$M, M_{f} \quad$ Rotor modal mass and fluid inertia effect. 


$\begin{array}{ll}D_{s}, D & \begin{array}{l}\text { Shaft damping and fluid film radial viscous } \\ \text { damping. }\end{array} \\ K_{s}, K_{s p}, K_{B} & \begin{array}{l}\text { Shaft stiffness, external spring frame stiffness } \\ \text { and fluid film radial stiffness. }\end{array} \\ \lambda & \begin{array}{l}\text { Fluid circumferential average velocity ratio. } \\ \text { Perturbation exciting force and unbalance } \\ f, F\end{array} \\ \text { circular force amplitude. } \\ \text { Rotor rotative speed and perturbation } \\ \text { frequency. } \\ \text { Rotor journal deflections in two lateral } \\ \text { directions. } \\ \text { Rotor response amplitude, phase and } \\ \text { perturbation force phase. } \\ \text { Mass and radius of perturbator unbalance. } \\ \text { Complex dynamic stiffness matrix. } \\ m, r \delta & \sqrt{-1} \\ \kappa & \end{array}$

Subscripts:

$f, b$

$x, y$

Perturbation forward and backward direction. Two lateral directions.

\section{References}

Bently, D. E., Muszynska, A., 1985. Perturbation Study of a Rotor/ Bearing System: Identification of the Oil Whirl and Oil Whip Resonances, Tenth Biennial ASME Design Engineering Division Conference on Mechanical Vibration and Noise, 85-DET-142, Cincinnati, Ohio, Sept.

Bently, D. E., Muszynska, A., 1988. Role of Circumferential Flow in the Stability of Fluid-Handling Machine Rotors, The Fifth Workshop on Rotordynamics Instability Problems in High Performance Turbomachinery, Texas A\&M University, College Station, Texas, NASA CP 3026, 16-18 May, pp. 415-430.

Bently, D. E., Muszynska, A., 1984. The Dynamic Stiffness Characteristics of High Eccentricity Ratio Bearings and Seals by Perturbation Testing, Workshop on Rotordynamic Instability Problems in High Performance Turbomachinery, Texas A\&M University, NASA CP2338, May.

Black, H. F., 1969. Effects of Hydraulic Forces in Annular Pressure Seals on the Vibrations of Centrifugal Pump Rotors, Journal Mechanical Engineering Science, vol. II, No. 2.

Franklin, W. D., Muszynska, A., and Bently, D. E., 1994. Parameter Identification with Noncollocation of Force and Measurement Locations Using Nonsynchronous Perturbation and Optimization Tech-

niques, ASME International Gas Turbine and Aeroengine Congress and Exposition, The Hague, Netherlands, 94-GT-127, 13-16, Jun.

Grant, J., Muszynska, A., Bently, D. E., 1993. Parameter Identification of a Rotor Supported in a Pressurized Bearing Lubricated With Water, 7th Workshop on Rotordynamic Instability Problems in High Performance Turbomachinery, Texas A\&M, College Station, Texas, May.

Hatch, C. T., Bently, D. E., 1995. Anisotropic Rotor Response and Probe Data Transformation to Improve Machinery Diagnostic Capability, Bently Rotor Dynamics Research Corporation Report, No. 1, Minden, Nevada, Jan.

Muszynska, A., 1994. Application of Multi-Mode Modal Models in Rotor Dynamics, ISROMAC 5.

Muszynska, A., 1988. Improvements in Lightly Loaded Rotor/Bearing and Rotor/Seal Models, Transaction of the ASME Journal of Vibration Acoustics, Stress and Reliability in Design, v. 110, No. 2, April.

Muszynska, A., 1986. Modal Testing of Rotor/Bearing Systems, The International Journal of Analytical and Experimental Modal Analysis, v. 1, No. 3, pp. 15-34.

Muszynska, A., 1995. Modal Testing of Rotors with Fluid Interaction, Internation Journal of Rotating Machinery, v. 1, No. 2.

Muszynska, A., 1986. Whirl and Whip-Rotor/Bearing Stability Problems, Journal of Sound and Vibration, U.K., vol. 110, No. 3, pp. 443-462.

Muszynska, A., Bently, D. E., 1995. Fluid-Induced Instabilities of Rotors: Whirl and Whip, Bently Rotor Dynamics Research Corporation Report, No. 3, Minden, Nevada.

Muszynska, A., Bently, D./E., 1990. Frequency-Swept Rotating Input Perturbation Téchniques and Identification of the Fluid Force Models in Rotor/Bearing/Seal Systems and Fluid Handling Machines, Journal of Sound Vibration, Vol 143(1), pp. 103-124.

Nordmann, Rainer., 1983. Identification of Modal Parameters of an Elastic Rotor with Oil Film Bearings, Journal of Vibration, Acoustics, Stress and Reliability in Design.

Poritsky, H., 1953. Contribution to the Theory of Oil Whip, Trans. of the ASME, No. 75.

Rogers, P. J., and Ewins, E. J., 1989. Modal Testing of an Operating Rotor System Using a Structural Dynamics Approach, Proceedings of the 7th IMAC.

Subbiah, R., Bhat, R. B., Sankar, T. S., 1989. Dynamic Response of Rotors Using Modal Reduction Technique, Journal of Vibration and Acoustics, vol. 111, October.

Tam, L. T., Przekwas, A., Muszynska, A., Hendricks, R., Braun, M. J., Mullen R. L., 1988. Numerical and Analytical Study of Fluid Dynamic Forces in Seals and Bearings, Trans. of ASME Journal of Vibration, Acoustics, Stress, and Reliability in Design, vol. 110, No. 3, July, pp. 315-325. 

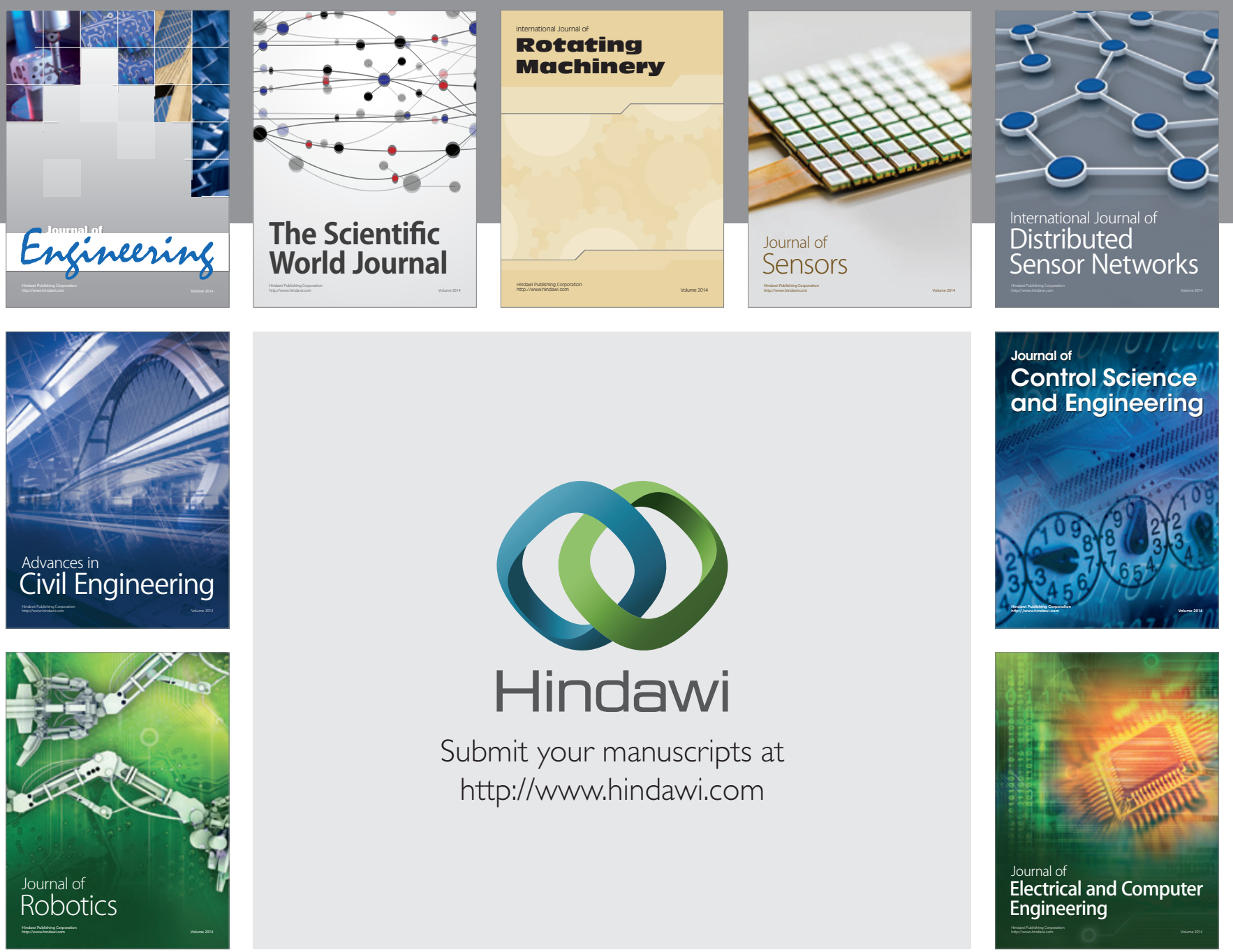

Submit your manuscripts at

http://www.hindawi.com
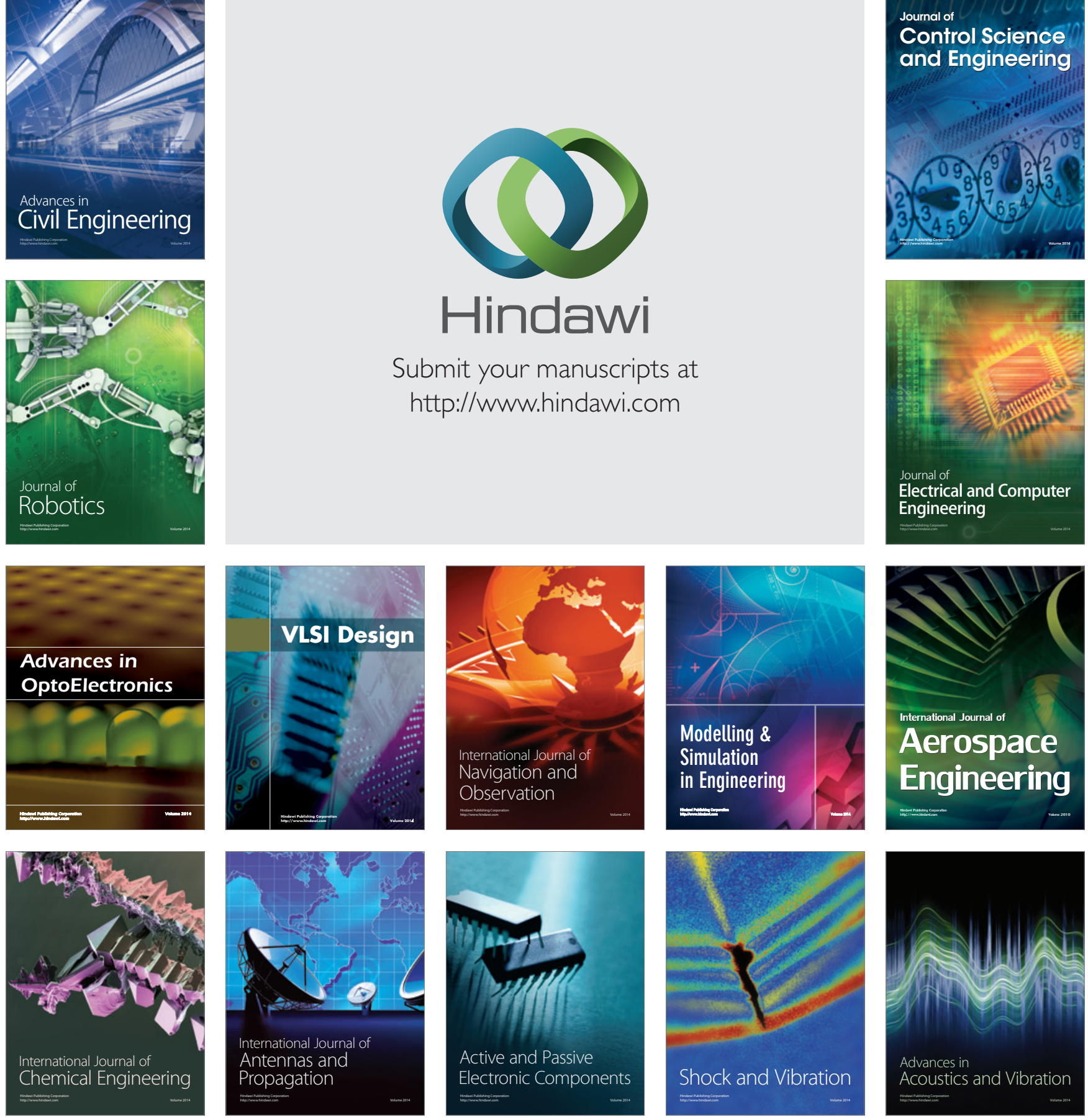